\title{
Decision support tool seeks to aid stream-flow recovery and enhance water security
}

by Adina M. Merenlender, Matthew J. Deitch and Shane Feirer

In many parts of coastal California, agricultural water needs during the summer are met by tapping riparian and groundwater resources, which has led to documented decreases in stream flow during the dry season. This has consequences for salmon, including sudden drying of habitat, higher water temperatures and changes in the invertebrate prey base. We developed a new, spatially explicit analytical tool to quantify and map human and environmental needs, model daily stream-flow rates, and estimate regulatory flow requirements and cumulative impacts of reservoirs. This tool is part of a decision support system that can be integrated in a Geographic Information System (GIS) with other restoration considerations. This research provides a basis for placing additional reservoir storage where projects are not likely to affect adult salmon passage, while reducing water demand from surface and subsurface flows during spring and summer, ultimately improving both habitat for salmonids and water supply for growers.

IN 2000 we reported on the expansion of vineyards into upland coastal watersheds (Merenlender 2000). With this expansion came changes in where, how and to what extent water is extracted from these watersheds for agriculture. Like most premium winegrape-growing regions around the world, coastal California has a Mediterranean climate with most rainfall in the winter months, followed by a dry period of up to 6 months. Stream flow follows a similar trend, with the major-

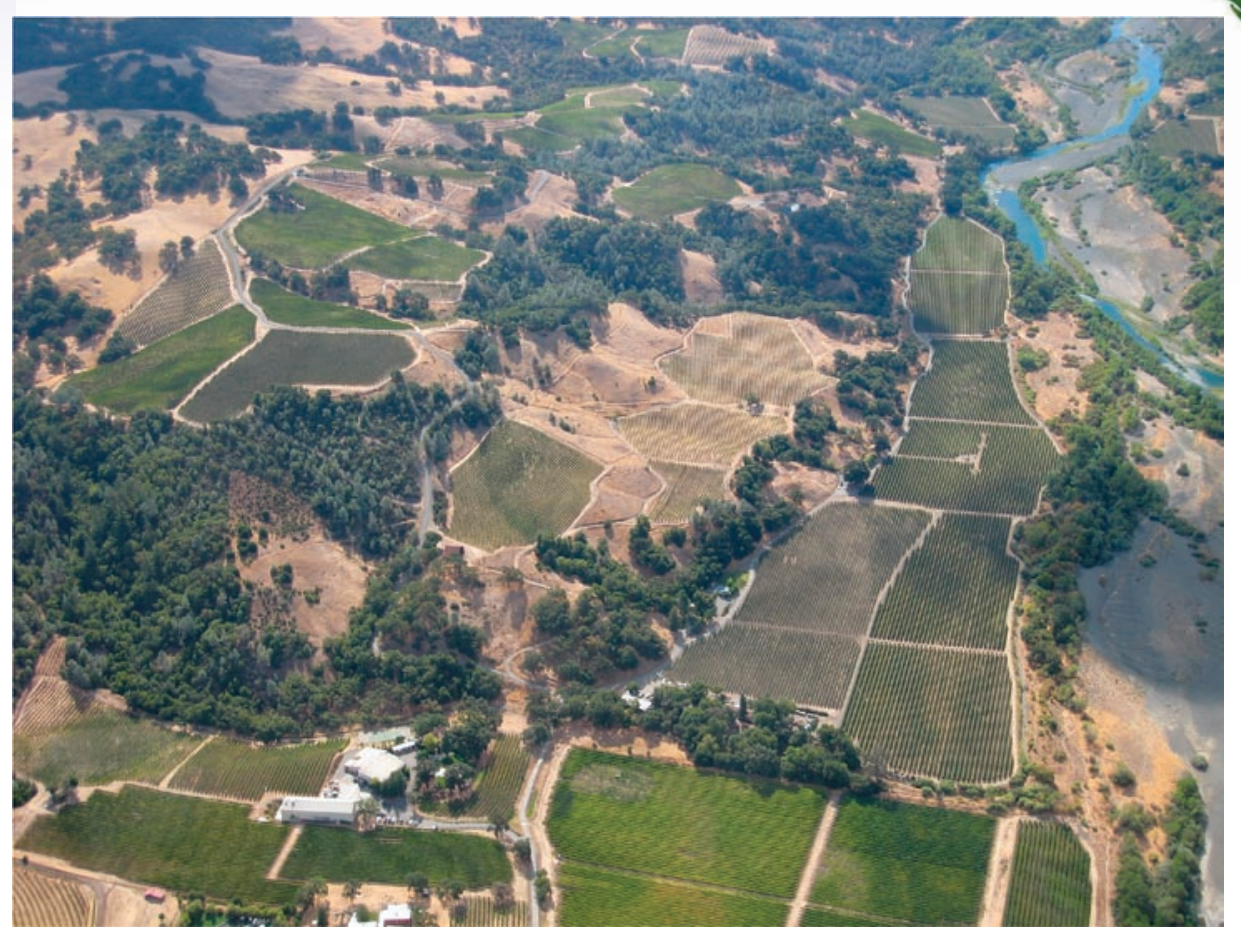

Vineyard managers need water for irrigation, as well as other purposes. In areas without reservoirs water often comes from local streams, which may also supply municipal water and provide salmon habitat. Balancing these competing water needs is a critical challenge facing the California wine-grape industry. Above, vineyards in the Russian River (top right) basin.

ity of flow occurring during winter and early spring, mostly as a series of highflow events separated by lower base flows in winter (fig. 1, page 149). When the rains end, stream flow then recedes gradually to reach or approach intermittence by late summer.

Precipitation is highly variable, seasonally and interannually, leading to an extremely uncertain renewable supply of fresh water. For example, deviations in mean annual flows of $30 \%$ or more from long-term annual averages are common, resulting in continual uncertainty about water supply for human use year to year (Deitch 2006).

Moreover, California's coastal regions often have complex geology that can lead to differences in stream flow within and between watersheds. Large, natural freshwater lakes are rare, and groundwater tends to be deep or restricted to bands along river corridors, so that humans rely heavily on streams for fresh water. Because water is not often available at the times when it is needed for irrigation, growers must carefully manage water supplies throughout the growing season. As a result, much of California's water needs are met by disseminating water stored behind large reservoirs. In areas not served by large water projects, including many coastal watersheds where premium wine grapes are grown, water is often diverted from streams or pumped from the ground, and if possible, stored on-site in small private reservoirs that growers establish for use during the dry season.

In addition to irrigation, grape growers may require water for other purposes, such as the protection of young buds from frost in early spring and relief from high summer temperatures. Analyses of seasonal water demand, which describe the fine-scale means through which needs are met, illustrate that direct pumping from streams can cause stream flows to drop by more than $90 \%$ locally, and downstream areas are also affected (Deitch et al. 2008). 


\section{Water in the Russian River basin}

Surface-water diversions may have the most substantial impacts on aquatic biota during spring and summer because stream flow is naturally low. The limited water available is critical for maintaining suitable habitat conditions, yet stream flow at this time is most susceptible to water diversions. In many parts of the Russian River basin, waterrights records predict that the demand for water during the spring and summer growing season exceeds supply, underscoring the imbalance between water need and supply (Deitch et al., in press); yet normal-year discharge (stream flow) during the wet season exceeds annual water removal (diversion) estimates by an order of magnitude (fig. 1).

In watersheds where water demand is high, surface-water diversions may accelerate drying over substantial stream reaches, reducing habitat for juvenile salmon and other aquatic species.

Secondary effects of stream drying, such as increased competition, higher water temperatures and increased predation risk may also occur where flows are reduced (Kocker et al. 2008).

The Russian River is home to three species of salmonids: coho salmon, chinook salmon and steelhead trout. All three species have experienced serious population declines and were listed under the federal Endangered Species Act in 2004. Although their life cycles are similar, they are not identical with respect to timing and physiological tolerance; therefore, each species requires special consideration for their recovery. The life cycles of native salmonids are well adapted to the natural hydrologic regime of the region (Moyle 2002) (fig. 1).

Winter floods maintain appropriate sediment distributions and prevent vegetation encroachment, while providing an environmental signal for adults to migrate from the ocean to coastal streams. Lower-velocity winter base flows between storm events allow adult salmon to swim upstream to spawning sites and provide suitable hydrologic conditions for egg laying and incubation. Spring flows maintain in-stream connectivity, allowing juvenile fish to migrate out, aerating eggs until fish emerge, and permitting microinvertebrates - important food for salmonids - to drift downstream. In summer, streams may become intermittent (interupted by dry areas) at which point pools continue to provide over-summering habitat. Flows resume again with the onset of winter rains, triggering the movement of adult salmon downstream (Kocker et al. 2008).

\section{State water regulation}

Since 1990, the State has hesitated to grant new or change existing water rights, in part because of concerns that additional appropriations will affect the in-stream flows necessary to sustain salmonid migration. As a result, there is a backlog of requests for additional

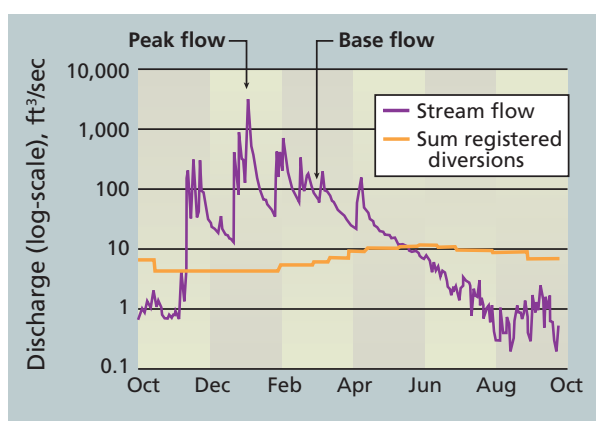

Fig. 1. Mean daily in-stream flows for 2004 from Maacama watershed, below a 43-squaremile catchment with $4.5 \%$ of its area in vineyards. $Y$-axis representing flow magnitude is on a log scale. To measure stream flows, Global Water WL15 pressure transducers were encased in high-pressure flexible PVC hose, attached to solid substrate and operated as stream-flow gauges according to standard USGS methods (Rantz 1982). Flow was measured using Price Mini and AA current meters at biweekly-to-monthly intervals to develop rating curves; instruments recorded stage at 10-minute intervals from November 2003 to September 2005. Arrows show examples of winter peak and base flows.

appropriative rights, many to increase the storage of winter runoff (SWRCB 1997, 2007). Until recently, the basis for these decisions hinged on draft joint guidelines from the California Department of Fish and Game (CDFG) and National Oceanic and Atmospheric Administration (NOAA) Fisheries Service to maintain winter flows sufficient for adult salmonid migration. In December 2007, the State proposed regulations for storing surface water in northern-coastal California, related
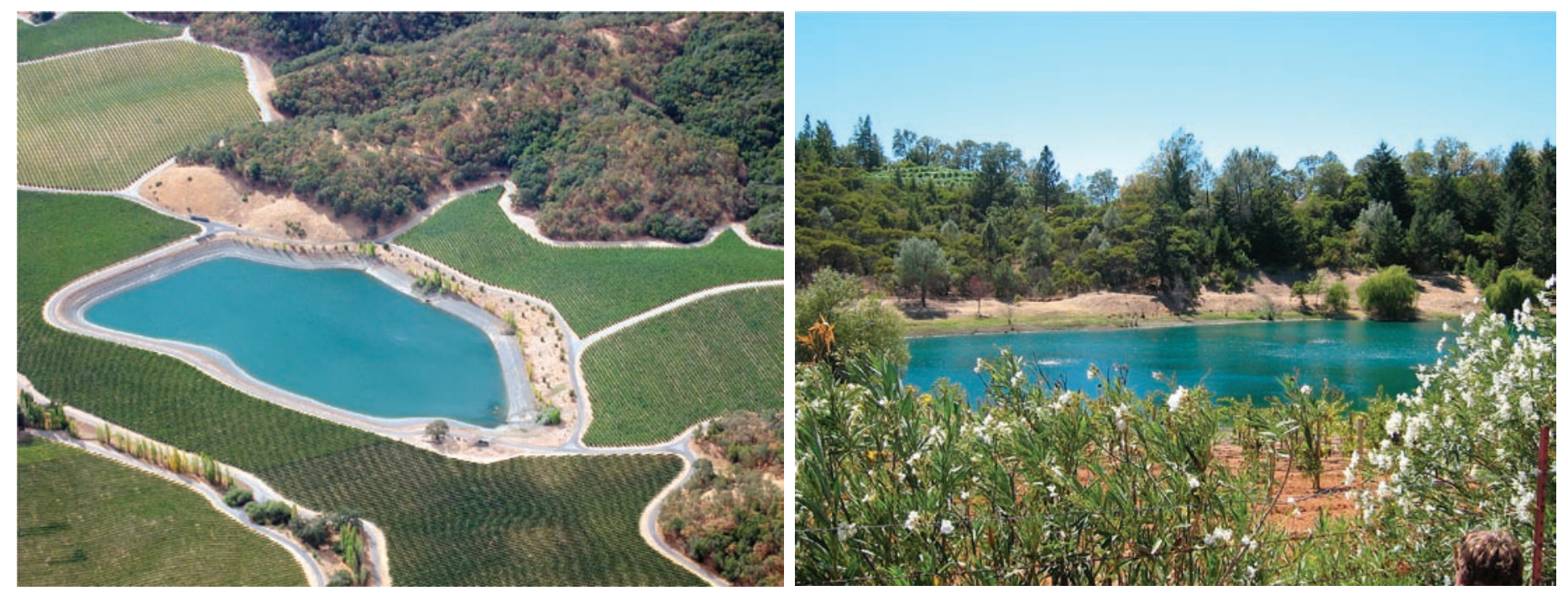

Small reservoirs, such as in the Dry Creek watershed (shown), can help grape growers to store winter rainfall for irrigation. They also safeguard creek flows that are critical for rearing salmonids in the dry season. 

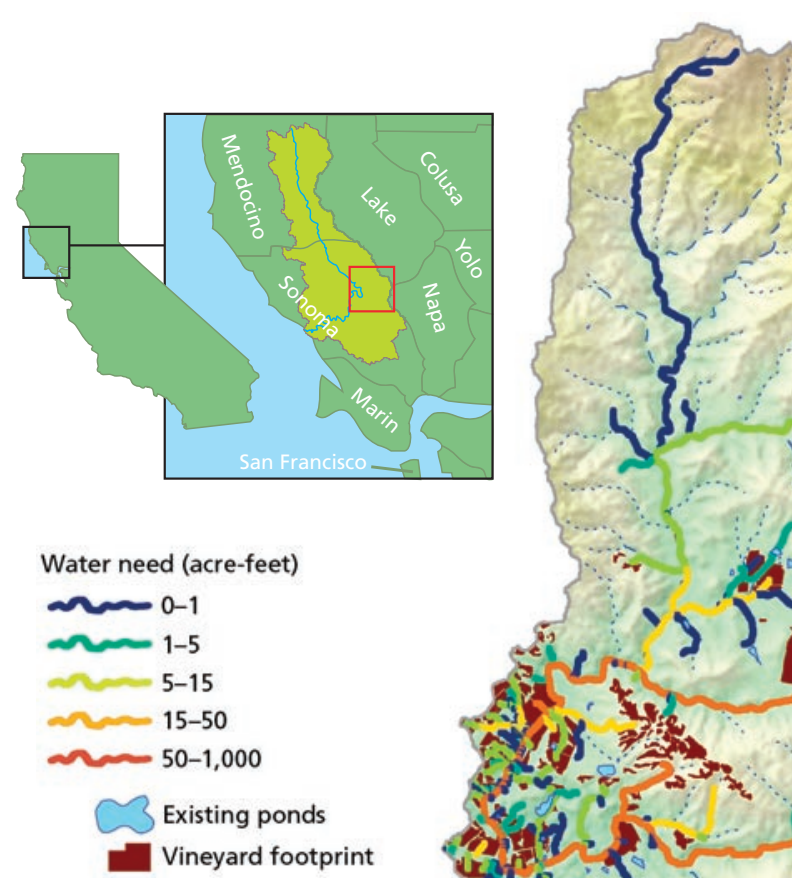

Fig. 2. Estimated cumulative need for water from upstream vineyards and rural residential development in the Maacama and Franz watersheds (tributaries to the Russian River, map inset), plotted along the stream network.

to aquatic ecosystem conservation, as part of its draft "Policy for Maintaining Instream Flows in Northern California Streams" (SWRCB 2007). They are being considered for adoption in 2008.

Because the proposed new policies for surface-water appropriations may not allow growers to meet agricultural water needs, we expect that they will continue to turn to alternative means, including riparian water diversions and groundwater pumping during the growing season, neither of which are subject to the same standards as appropriations (Sax 2002). We theorize that it may be more useful to consider the impacts of small water projects relative to cumulative impacts on discharge through the year, rather than to set a required flow condition that uniformly protects winter flows sufficient for adult salmonid migration at all locations.

We describe spatially explicit models for agricultural and rural-residential water needs, daily stream flow throughout a watershed, proposed environmental stream-flow requirements, and cumulative impact analysis of small reservoirs on stream flow. Integrating this information across entire water- sheds where there are no large, centrally controlled reservoirs is essential for evaluating the environmental and social tradeoffs with different watermanagement schemes widely implemented across coastal California.

\section{Estimating dry-season water needs}

A Sonoma County vineyard map based on orthorectified aerial photos from 1993, 2000, 2002, 2004 and 2005, as well as oblique aerial photos from 2006 (59,000 acres in Sonoma County; see California Agriculture Vol. 62, No. 1, page 11; and Merenlender 2000), were used to estimate the agricultural water need by multiplying each acre by twothirds acre-foot. (This estimate does not include additional water needed in areas where overhead sprinkling is required for frost protection [Lewis et al. 2008]). We also added 0.226 acre-foot per rural residential unit to account for outdoor water use by the average home. Rural residential units were mapped based on county parcel and assessor's data, which includes units per parcel. Estimated water need was then summarized for each individual land parcel.
Reservoirs were also digitally mapped from aerial photographs, and the surface area for each reservoir was used to estimate total volume based on an empirical statistical relationship between a sample of recorded volumes and surface area $(n=100)$ from the State. The estimated volume of winter water storage in existing reservoirs on a given parcel was subtracted from the estimated water need per parcel as described above. We then calculated total water need per parcel not met by winter water storage. Total water need for each land parcel was then summed downstream using a flow accumulation model to determine the cumulative need through the entire drainage network (ESRI 2006) (fig. 2).

\section{In-stream flow thresholds}

To compare the amount of water permitted for removal under the new proposed in-stream flow regulations with amounts permitted under existing guidelines, we mapped the regulatory flow thresholds based on these two policies and estimated allowable withdrawals. The new proposed regulations restrict water diversion actions to the winter rainy season, Oct. 1 through March 31. Also, a specific flow threshold must be exceeded before water can be diverted from the stream. This flow threshold is defined as the minimum flow corresponding to a depth that allows salmonids to migrate upstream, preserving the potential for them to find adequate spawning reaches. This standard, the minimum bypass flow, is calculated as:

$$
\mathrm{Qmbf}=9.4 \mathrm{Qm}(\mathrm{DA})^{-0.48}
$$

where Qmbf is minimum bypass flow in cubic feet per second; Qm is mean annual unimpaired flow in cubic feet per second; and DA is the watershed drainage area in square miles (for streams with watershed area less than 295 square miles). If the upper limit of anadromy (the point above which the stream is no longer considered salmo- 

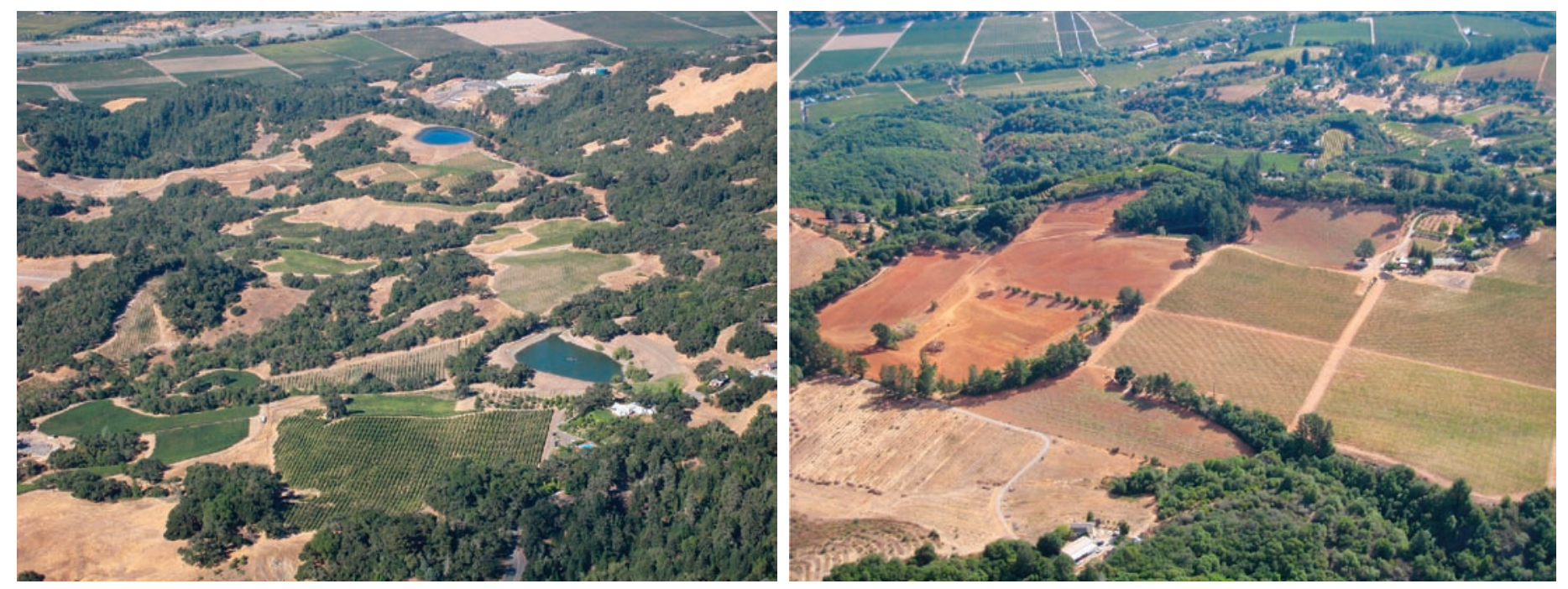

Aerial photography of vineyards, coupled with stream-flow data, is being used to develop models that will help growers and regulators to better plan for future water needs and salmon recovery. In, left, Alexander Valley and, right, Dry Creek, vineyards grow on hillsides.

nid habitat, defined as a $12 \%$ gradient over a length of 100 meters; SWRCB 2007) is downstream of the point of diversion, the drainage area at the upper limit of anadromy may be used.

Part of the proposed regulation is related to the total amount of water that can be diverted at any time. This is intended to protect peak storm flows, which are important for moving large materials in the stream and reshaping stream channels. This standard, described as the maximum cumulative diversion criterion (Qmcd), is defined as 5\% of the 1.5-year instantaneous peak flow at the proposed point of diversion (this peak flow rate is estimated using historical data). We calculated the minimum bypass flow and maximum cumulative diversion in the GIS for every point in the drainage network to examine how the conditions for diversion established by the regional protective criteria vary spatially; where and when stream flow is expected to exceed these threshold levels; and how much water could be diverted when these thresholds are exceeded.

We used the GIS to map the amounts of surface water that would be allowed under these proposed policies for all points across the drainage network, using the following steps: (1) estimating mean daily flow from the normal-year U.S. Geological Survey (USGS) stream-flow data according to watershed area and precipitation differences for all points throughout the drainage network; (2) calculating the Qmbf and Qmcd according to the definitions above; (3) counting the number of days at each point when the expected mean daily flow exceeded the calculated minimum bypass flow threshold over the diversion season, using an average rainfall hydrograph from the historical period of record (1966); and (4) multiplying the number of days by Qmcd (up to the defined Qmbf).

For example, we used stream-flow data at the centrally located Maacama Creek near Kellogg USGS gauge (number 11463900, in eastern Sonoma County, with a 20-year period of record from 1962 to 1981) for a normal-type year (1966, a year with median annual discharge over the period of record), and scaled this stream-flow data by watershed area and mean annual precipitation to create a daily stream-flow value for each point in the drainage. We then counted the number of days for each stream segment where stream flow exceeded Qmbf to determine the number of days during the winter diversion season that water users could divert.

For comparison, we calculated the maximum annual diversion for each point in the Maacama Creek drainage network using a standard of no more than $10 \%$ of the winter-season discharge, approximately equivalent to the maximum allowable diversion volume given in the 2002 draft joint guidelines (CDFG/NMFS 2002). This comparison allowed us to quantify the differences between policies relative to the impacts they have on potential appropriators and relative to their location in the watershed.

\section{Cumulative small-reservoir impacts}

We also created a model using our GIS to examine the cumulative impact of small surface reservoirs on stream flow through the year, as reservoirs fill from the onset of the rainy season in fall. Estimated reservoir volumes (mean $=$ 28 acre-feet, median $=9$ acre-feet; $91 \%$ of 1,087 mapped reservoirs are less than 50 acre-feet) in the Sonoma County portion of the Russian River watershed were incorporated into our watershed model, and the upstream catchment area was calculated for each reservoir. We modified the digital elevation model by inserting existing mapped reservoirs so that water flowed from the upper watershed into the reservoirs until they filled and then out the lowest point of the reservoir into the downstream drainage network.

The start of the delineated network began at the reservoir outlets. All segments of the stream network had the maximum flow accumulation value from upstream assigned, and the hydrologic network was then exported from ArcGIS (ESRI 2006) as lines and points into a spatial database. The database files related to the shapefiles were then imported into a Microsoft Access database, which manipulated the stream network created by the GIS. The database was then used to estimate flow across the watershed. The model assumes that reservoirs are empty at the onset of the water year, and that small dams block discharge from up- 


\section{Collaborative conservation helps achieve regional water-quantity goals}

\author{
T and and water conservation in places \\ Luch as coastal California, which
} is almost entirely comprised of private land, cannot occur without landowner participation. We are engaged in a collaborative conservation process with a public interest group called the Salmon Coalition, to facilitate landowner participation in transformative restoration. This coalition represents a growing demand for more adaptive local approaches to resource management.

The Salmon Coalition was formed in 2006 to increase communication among the private landowners of Dry Creek, Knights and Alexander valleys (northern Sonoma County); resource agency staff (the National Oceanic and Atmospheric Administration and the California Department of Fish and Game); the Sonoma County Water Agency and their urban clients (nine water districts in Sonoma and Marin counties); environmental interest groups; and other stakeholders. Its goal is to set restoration priorities for salmon recovery while protecting and hopefully improving water security for rural and urban uses, and providing certainty to private landowners dealing with the federal Endangered Species Act (ESA). The coalition is an example of a policy-based initiative that utilizes stakeholder participation to design plans intended to protect habitat as compensation for regulatory protection against potential ESA violations (Cestero 1999).

Collaborative conservation is increasingly popular as decision authority on how to implement species recovery devolves from government to public stakeholders. An increased emphasis on farmer participation in water management planning is now part of the 2008 Farm Bill. The Agriculture Water Enhancement Program changes existing ground- and surface-water conservation programs to allow cooperative agreements between the Secretary of Agriculture, multiple producers, government entities and tribes, with $\$ 70$ million for each of fiscal years 2008 through 2012. Collaborative conservation will provide the basis for these agreements.
The outcomes of collaborative conservation are generally untested. In an attempt to define a common language and share lessons from case studies, a Sonoran Institute report called "Beyond the Hundreth Meeting" focused on public land issues, offering guidelines for improving the success of public planning processes (Cestero 1999). Place- or community-based efforts are distinguished from those that address a specific policy or interest-based initiatives, like the Salmon Coalition.

Cestero (1999) also reports that place-based efforts work best if they are led by local participants rather than government representatives, and take place in an open and inclusive process that can accommodate a full range of perspectives - including government representatives. It is also better if participants do not try to represent larger interest groups, because confusion can arise when individuals are held accountable for the larger, diverse group, some of whom will feel their interests were not well represented. In addition to completing the desired projects, collaborative conservation increases capacity among community residents to respond to external and internal stresses that will inevitably arise. This capacity can help prevent future problems from becoming crises.

Collaborative conservation groups that focus on smaller areas are more likely to succeed, because those involved can relate to the landscape in question and regular participation from people spread across a large geographic area is not required (Cestero 1999). The Quincy Library Group in Northern California, for example, was a group of approximately 30 people who developed a plan for 2.5 million acres of public forestland. Ultimately, the plan did not adequately address the diverse interests represented in this large and relatively populated area (Duane 1997). Such larger-scale conservation projects are better addressed through a network of local efforts (Cestero 1999).

The Salmon Coalition is primarily focused on two subwatersheds within the Russian River. Equally important, the

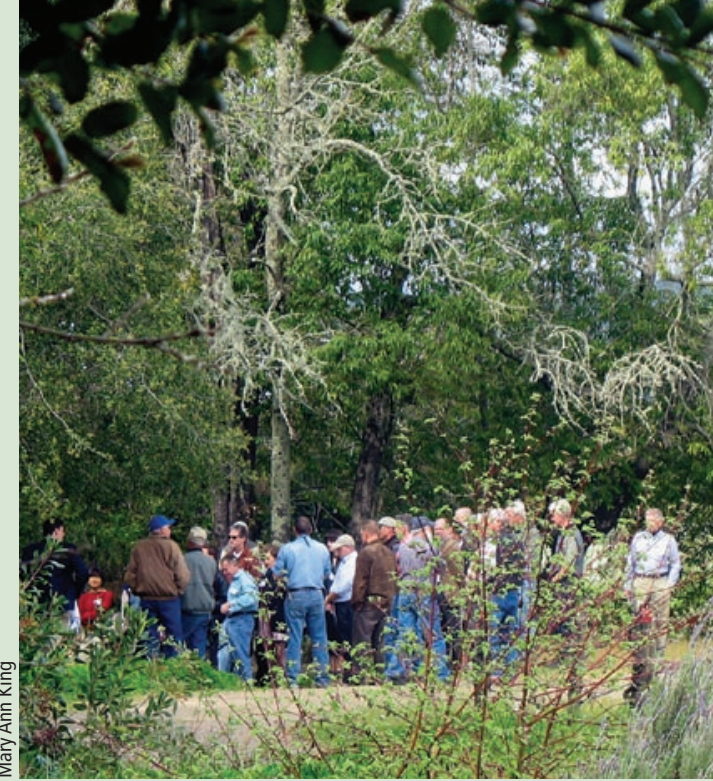

The Salmon Coalition and Trout Unlimited hosted a "Water and Wine" field tour.

Salmon Coalition has agreed to a participatory research effort that will greatly increase understanding of the various ways that water is managed across private lands. One way to empower a group early on is to begin collecting and evaluating existing information to increase understanding of the system (Cestero 1999). Wine-grape growers are providing us with information on water management practices, and private landowners will provide access for further stream-flow monitoring. Without this cooperation, local information could not be collected and we would continue to rely on coarse assumptions and management models that are ill-suited for such a complex system. The data will enhance our understanding of human-ecosystem interactions - a necessary step to better inform future water management and policy decision-making.

We intend for these efforts to help the State and local stakeholders resolve problems over additional requests for appropriative rights to store more water during the rainy season. Our data analysis and models will also be used by Sonoma County to improve its estimates of available flows for ecological processes (including enhancing salmonid recovery efforts) and municipal uses.

- A.M. Merenlender

\section{References}

Cestero, B. 1999. Beyond the Hundreth Meeting: A Field Guide to Collaborative Conservation on the West's Public Lands. Sonoran Institute. Tucson, AZ. 81 p.

Duane TP. 1997 Community participation in ecosystem management. Ecol Law Q 24:771-96. 
stream until the reservoir fills (that is, when the cumulative discharge volume from the upstream watershed equals the volume of the reservoir), at which time the upstream drainage network is reconnected hydrologically with the rest of the watershed.

We then used the flow accumulation model to determine the fraction of discharge accumulating from unimpeded parts of the watershed, and adjusted this fraction to reflect flow conditions as reservoirs fill through the winter. In addition to showing local effects of reservoirs (i.e., immediately below the dam), the model is designed to illustrate the cumulative impacts of reservoirs on stream flow anywhere in the drainage network, including flow from unimpaired streams.

\section{Calculating water needs}

Our calculated estimate of total water need ranged from approximately 1,500 to 4,500 acre-feet at the bottom of the major tributaries to the Russian River. This is the estimated demand that is currently unmet by storage ponds and may be extracted during the dry season from surface water, subsurface stream flow and groundwater.

Policy scenarios. Analysis of the new proposed policy restrictions reveals that in headwater streams where new vineyards rely on freshwater resources, surface-water projects would only be permitted to remove water for 2 to 8 days in a normal year during the rainy season in Maacama Creek (fig. 3). Expanding to a broader area, this analysis reveals that an estimated $57 \%$ of the drainage network across the Russian River in Sonoma County would be restricted to 0 to 4 days for the diversion of winter stream flow. This is because

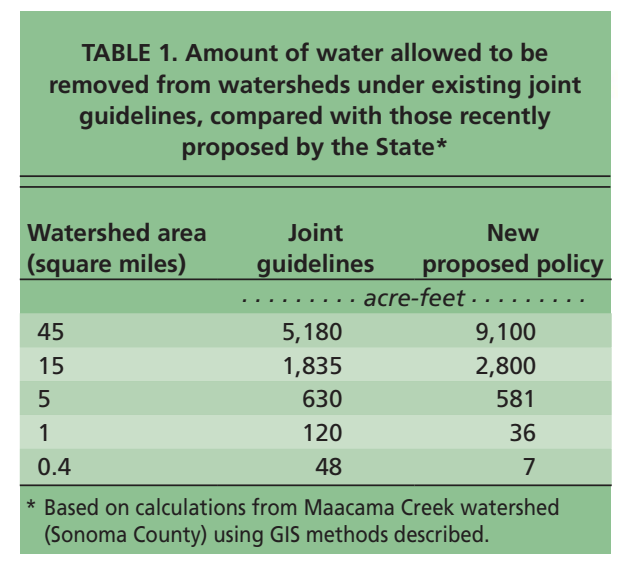

much $(79 \%)$ of this area is made up of watersheds less than 0.63 square mile (1 square kilometer) where first-order streams (unbranched tributaries) predominate. We compared the estimated amount of winter surface water allowed to be stored, based on the existing joint policy guidelines, with those proposed by new regulations (table 1). The observed differences for small headwater streams are important because more than $90 \%$ of the 1,000 reservoirs in the Sonoma County portion of the Russian River watershed have upstream catchments of less than 0.5 square mile.

Small reservoirs and winter flows. Using normal-year flow data from a time of few dams and diversions (representing unimpaired flow), the model indicates that early-season stream flow in some major tributaries to the Russian River may be reduced by as much as $50 \%$ and that these impaired sites are predominately found in small watersheds (fig. 4A). Therefore, we expect that earlyseason rains may produce only a fraction of the stream flow that would be expected in the absence of small reservoirs.

However, the impact diminishes as the rainy season progresses because

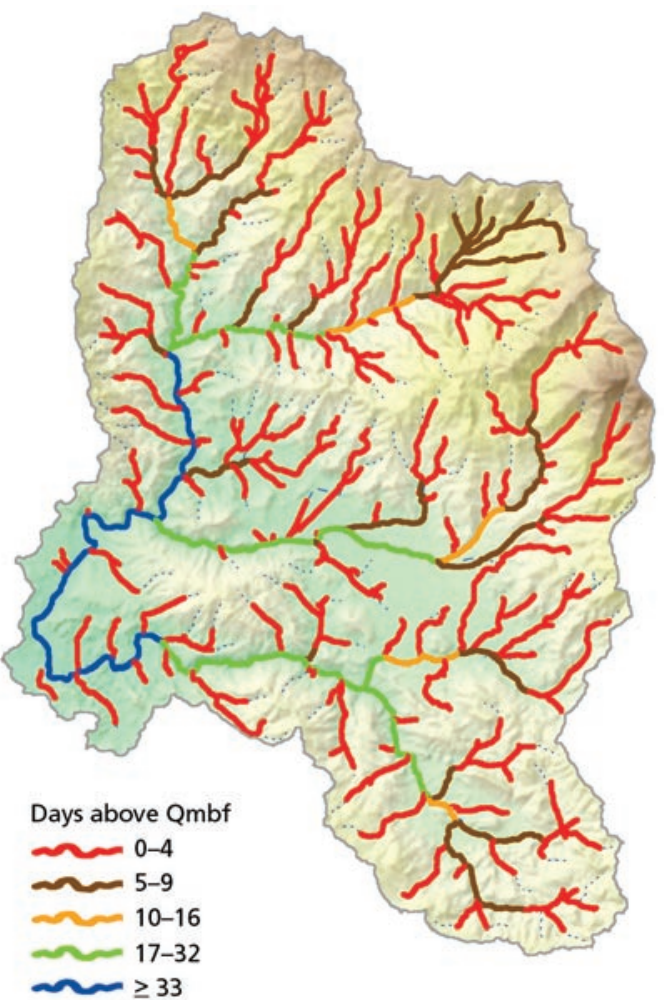

A Fig. 3. Number of days per year that estimated flow exceeds proposed new instream flow policy's minimum-bypass threshold along the Franz and Maacama drainage network. Under the proposed policy, surface-water removal would be allowed in $57 \%$ of the continuously mapped drainage area for $0-4$ days, $19 \%$ for $5-9$ days, $7 \%$ for $10-16$ days and $9 \%$ for $17-32$ days. Only $8 \%$ of the mapped area would allow surface-water removal for 33 days or more.
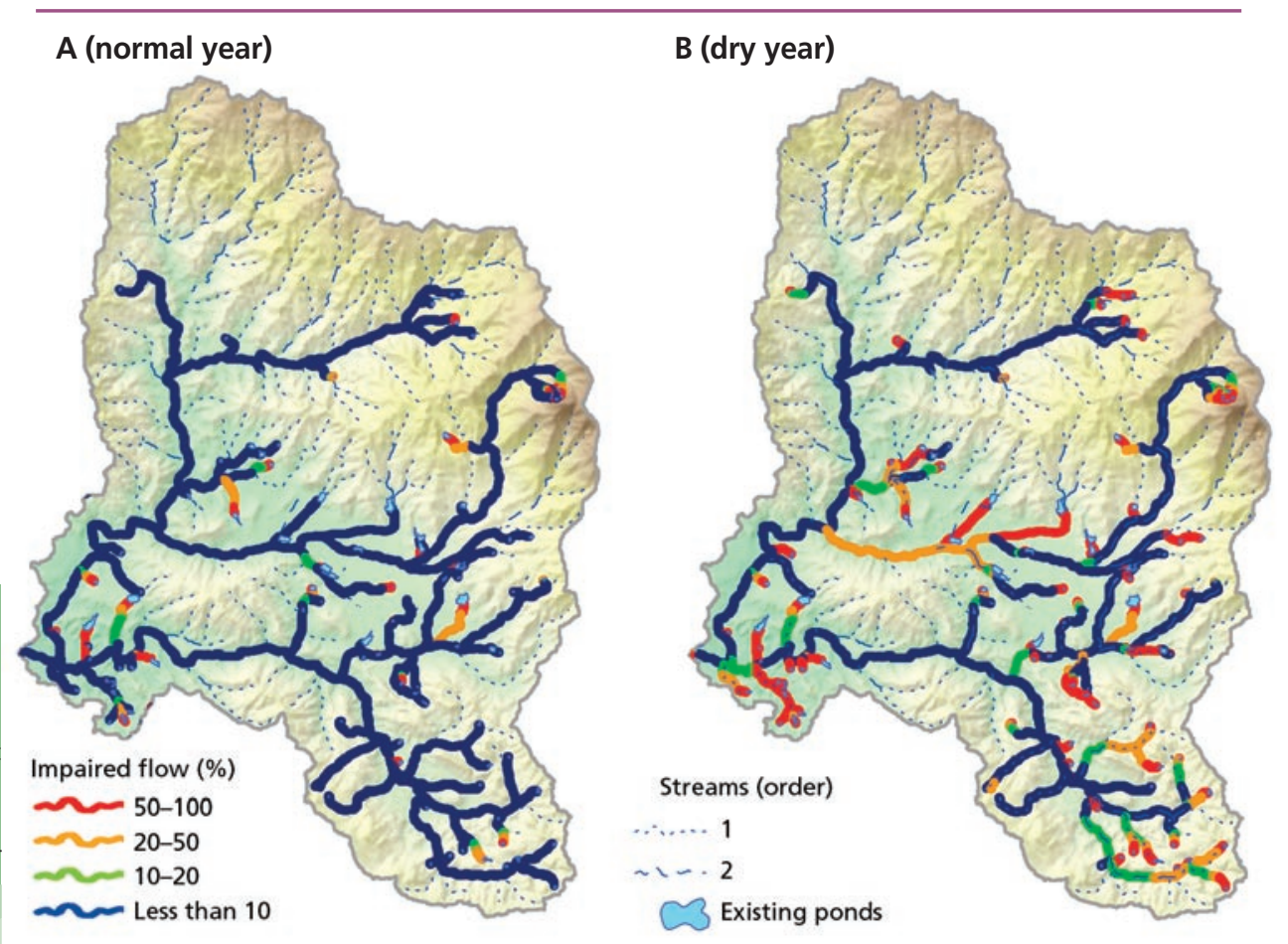

Fig. 4. Levels of flow impairment due to a reservoir's impeding winter flows estimated for week 15 of the water year, based on (A) 1966, a nomal-year hydrograph (median annual discharge) and (B) a dry-year hydrograph (1971, lower-quartile annual discharge, based on historical data). Higher levels of impairment for small reservoirs can be seen for this very dry year. Stream order is also mapped: unbranched tributaries are first order, two first-order streams join together to form a second-order stream, and so on. 


\begin{tabular}{|c|c|c|c|c|c|c|}
\hline \multirow[b]{2}{*}{ Impairment (\%) } & \multirow[b]{2}{*}{ Impaired drainage } & \multicolumn{5}{|c|}{ Upstream catchment area (square miles) } \\
\hline & & $<0.4$ & $0.5-4$ & 4.1-15 & $15.1-40$ & $>40.1$ \\
\hline & 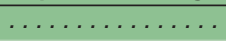 & ...... & $\ldots \ldots \%$ & $\ldots \ldots$ & $\ldots \ldots \ldots$ & $\ldots \ldots$ \\
\hline$<10$ & 46 & 17 & 41 & 18 & 9 & 15 \\
\hline $10-20$ & 17 & 28 & 34 & 18 & 10 & 10 \\
\hline $20-50$ & 15 & 37 & 30 & 10 & 3 & 20 \\
\hline$>50$ & 22 & 55 & 26 & 5 & 4 & 10 \\
\hline
\end{tabular}

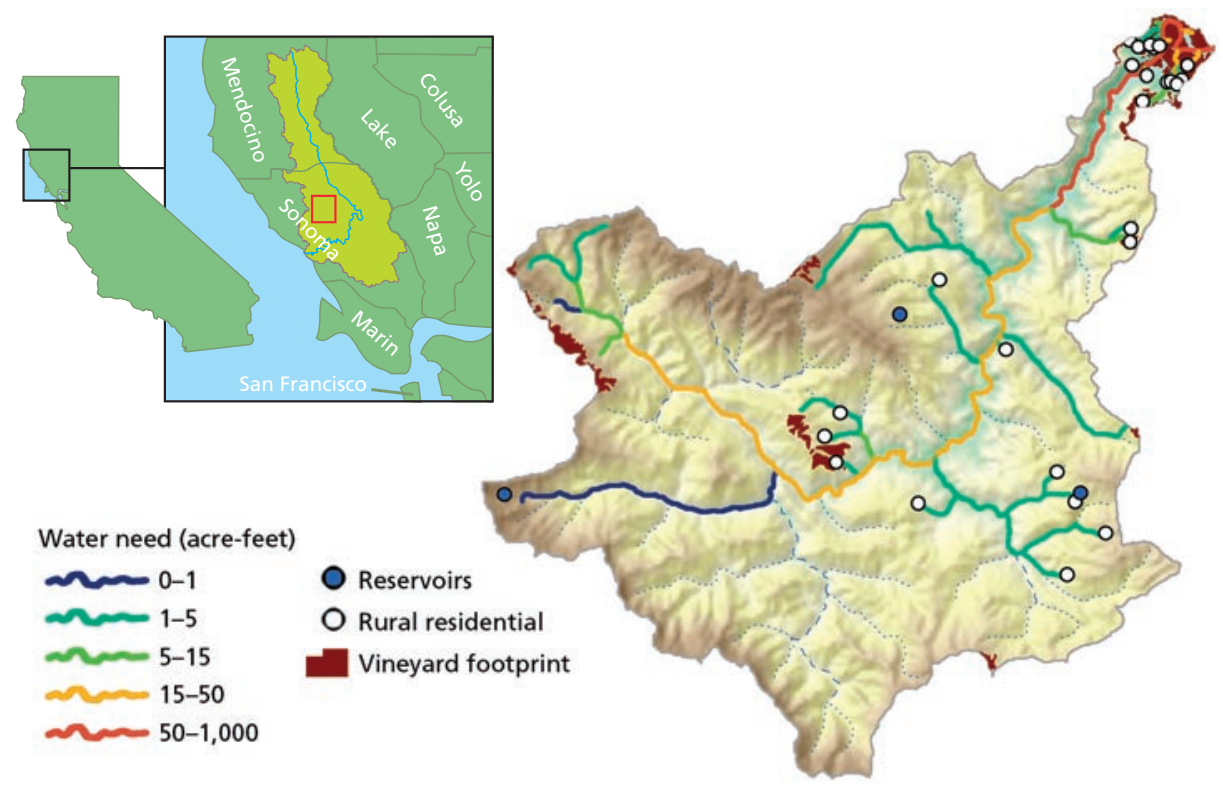

Fig. 5. Estimated need for water not met by existing winter water storage along Pena Creek, tributary to Dry Creek, from residential areas and two upland vineyards.

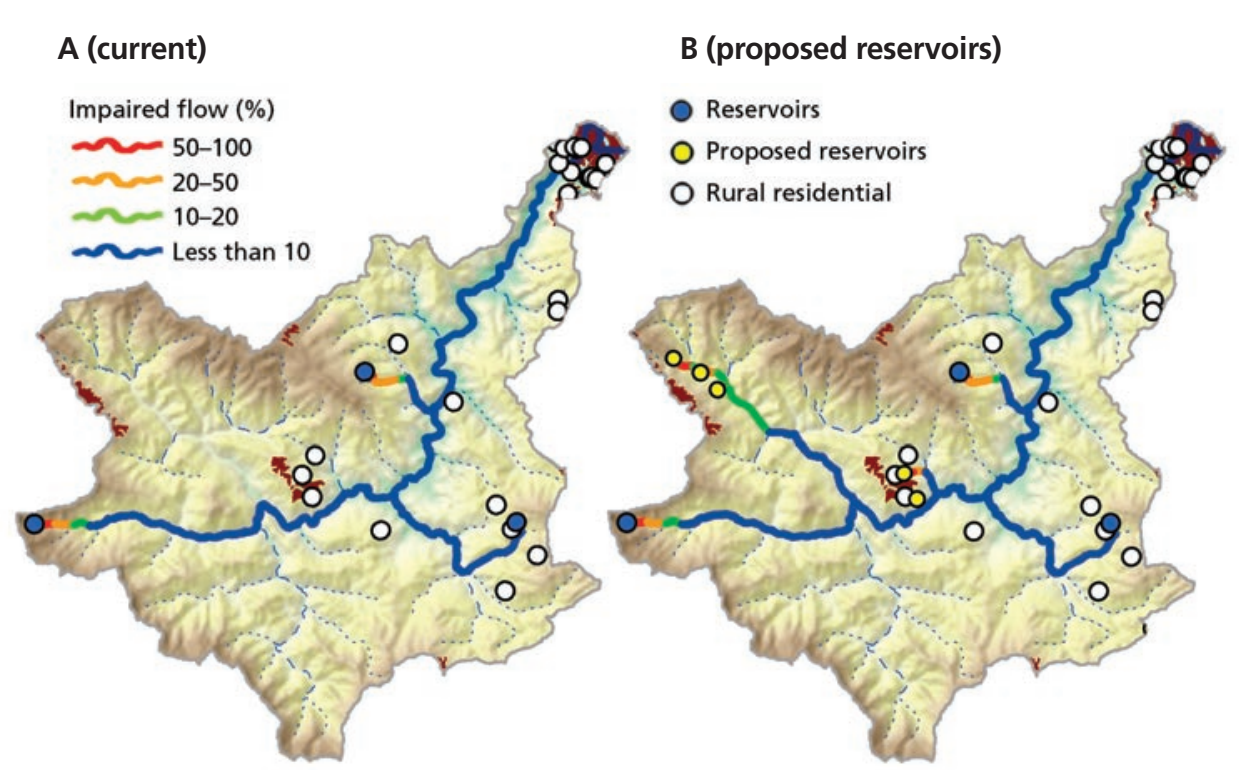

Fig. 6. (A) Impacts of the few existing reservoirs (blue dots) along this creek. (B) Impacts estimated to occur if small, 20 acre-foot reservoirs (yellow dots) were placed on vineyard parcels to meet estimated water needs during the dry season from winter runoff early in the season (day 63 of the water-year based on Pena gauge station data for 1981, a normal rainfall year). reservoirs fill over time: stream flow is reduced by less than $10 \%$ by the end of December for most reaches in normal rainfall years because many reservoirs have filled by this point (fig. 4A). Also, $90 \%$ of the most-impaired sites are in very small watersheds because reservoirs in the Russian River watershed are commonly focused in headwater streams (table 2). The window for upstream bypass is larger lower in the watershed as compared to upper tributaries, and these reservoirs are less likely to affect the ability of salmon to migrate through lower reaches to find suitable spawning tributaries. The impacts increase when the driest year on record is used to run this reservoir impacts model (fig. 4B). This modeling effort can help reveal where additional reservoirs for storing winter rainfall can be placed to minimize impacts on adult salmon passage and relieve the effects of current management practices on spring and summer stream flow.

A hypothetical example illustrates the tradeoffs between site-level impacts on winter flows from increasing reservoir storage in upland sites for vineyard use, and reductions in water demand over the dry season (figs. 5-7). This upland tributary to Dry Creek in the Russian River basin currently has two upland vineyards requiring an estimated 90 acre-feet of water for irrigation (fig. 5). Reservoirs for winter water storage currently do not exist and the water used is pumped on demand during the dry season, which could reduce intermittent summer flows. To offset impacts on summer flows, small reservoirs averaging 20 acre-feet in size can be hypothetically placed in the upper watershed where they are needed. This reservoir impact model can then be run to estimate the impacts to winter flows (fig. 6), which are limited to just downstream of the storage pond. These small, distributed reservoirs can store sufficient winter water to offset the water needs of these vineyards (fig. 7) and offset the demand for water in the summer.

\section{Water management framework}

By quantifying and mapping estimated human needs, environmental 


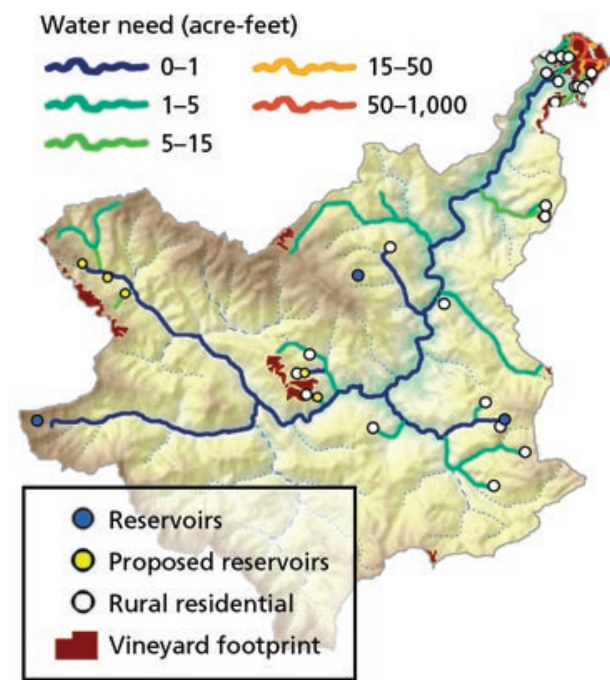

Fig. 7. Greatly diminished water need during the dry season for Pena Creek after the hypothetical placement of several upland reservoirs.

needs and reservoir impacts - and presenting them visually with other restoration considerations - we can provide decision-support for informing water management and salmonid restoration in the wine country of northern-coastal California.

In particular, we demonstrate that these tools can be used to evaluate various water-policy scenarios (i.e., changes to bypass flow thresholds), estimate the cumulative effects of water extraction methods on the natural hydrograph across a large spatial scale (including temporal variation), and provide information for the watershed-level planning required to recover environmental flows for salmonids. Given highly variable year-to-year rainfall patterns it is important that the modeling tools described here allow hydrographs based on low, moderate and high rainfall years to be used to evaluate the impacts of water management. These applications are relevant to the State's water-allocation decision-making process, resource agencies involved in salmonid recovery planning, and private landowners interested in water management solutions and habitat restoration. These models can be compared with existing data on salmon habitat, physical barriers and other mapped information including existing and proposed appropriative water rights, to help prioritize stream-flow restoration needs for salmon recovery.

Our model expresses water needs over a coarse annual scale, while ecological requirements operate at finer scales. However, we are working with the agricultural community to provide increased insight into the timing of water needs throughout the growing season (see sidebar, page 152). Decisions about reservoir management and the amount of water needed during the growing season are currently made based on uniform assumptions, but we believe that better decisions can be made by working with growers to parameterize the models based on their actual water-use practices.

The models presented here quantify the tradeoffs for both wine-grape growers and salmonid recovery efforts, between storing more water in the winter and pumping on-demand year-round to meet agricultural and residential water needs. Environmental flows should be

\section{References}

[CDFG/NMFS] California Department of Fish and Game and National Marine Fisheries Service. 2002. Guidelines for Maintaining In-stream Flows to Protect Fisheries Resources Downstream of Water Diversions in Mid-California Coastal Streams (draft). Santa Rosa, CA.

Deitch MJ. 2006. Scientific and Institutional Complexities of Managing Surface Water for Beneficial Human and Ecosystem Uses under a Seasonally Variable Flow Regime in Mediterranean-Climate Northern California. PhD dissertation, UC Berkeley.

Deitch, MJ, Kondolf GM, Merenlender AM (in press). Surface water balance to evaluate the hydrological impacts of small in-stream diversions and application to the Russian River basin, California, USA. Aquat Conserv: Marine Freshwater Ecosys.

Deitch MJ, Kondolf GM, Merenlender AM. 2008. Hydrologic impacts of small-scale in-stream diversions for frost and heat protection in the California wine country. River Res Applicat 24.

[ESRI] Environmental System Research Institute. 2006. ARCGIS (Version 9.2) [Computer software]. Redlands, CA. www.esri.com.

Kocker SD, Thompson LC, Harris RR. 2008. Living Among the Fishes: A Guide to Conservation of Fish Habitat in Developed Landscapes. UC ANR Pub 8279. Oakland, CA

Lewis DJ, McGourty G, Harper J, et al. 2008. Meeting irrigated agriculture water needs in the Mendocino County portion of the Russian River. UC considered across the entire year to improve salmonid habitat. This framework can help to identify potential solutions for ecological and economic interests in the region, helping to prevent future regional environmental and social crises that can arise around salmon and other endangered-species recovery programs.

A.M. Merenlender is Cooperative Extension Specialist, Integrated Hardwood Range Management Program, Department of Environmental Science, Policy and Management (ESPM), UC Berkeley; M.J. Deitch is Senior Environmental Scientist, Center for Ecosystem Management and Restoration, Oakland (formerly Postdoctoral Fellow, ESPM, UC Berkeley); and S. Feirer is GIS analyst, UC Hopland Research and Extension Center. This research was funded in part by the U.S. Environmental Protection Agency (STAR grant G4K10732), and Sonoma County Water Agency. Our colleagues at UC Berkeley have been instrumental in developing some of these ideas: Juliet Christian-Smith, Ted Grantham, G. Matt Kondolf, Ruth Langridge, David Newburn and Vince Resh. We also thank the Salmon Coalition for their interest in applying our research.

Cooperative Extension Mendocino County, UC Davis Department of Land, Air and Water Resources, and UC Kearney Agricultural Center. 56 p.

Merenlender AM. 2000. Mapping vineyard expansion provides information on agriculture and the environment. Cal Ag 54(3):7-12.

Moyle PB. 2002. Inland Fishes of California. Berkeley, CA: UC Press. $502 \mathrm{p}$

Rantz SE. 1982. Measurement and computation of streamflow. Vol 1. Water Supply Paper 2175. US Geological Survey. Washington, DC. 284 p. http://pubs. usgs.gov/wsp/wsp2175/html/WSP2175_vol1_pdf. html.

Sax JL. 2002. Review of the Laws Establishing the SWRCB's Permitting Authority Over Appropriations of Groundwater Classified as Subterranean Streams and the SWRCB's Implementation of Those Laws. State Water Resources Control Board. Sacramento, CA. www.waterrights.ca.gov/hearings/SaxReport/ SubStreamRpt(2002-01-20).pdf.

[SWRCB] State Water Resources Control Board. 1997. Staff Report on the Russian River Watershed. SWRCB Division of Water Rights. Sacramento, CA. www. waterrights.ca.gov/coastal_streams/docs/russianriver/ russianriver_rpt081597.pdf.

SWRCB. 2007. Policy for Maintaining In-stream Flows in Northern Coastal California Streams. December 2007 draft. Division of Water Rights. Sacramento, CA. www.waterrights.ca.gov/docs/instreamflow/ draftpolicy2007dec/2_policy_updated010708.pdf. 